(C) 2006 IEEE. Personal use of this material is permitted. Permission from IEEE must be obtained for all other uses, in any current or future media, including reprinting/republishing this material for advertising or promotional purposes, creating new collective works, for resale or redistribution to servers or lists, or reuse of any copyrighted component of this work in other works. 


\title{
Development of a PM Transverse Flux Motor with Soft Magnetic Composite Core
}

\author{
YouGuang GUO, Member, IEEE, Jian Guo ZHU, Senior Member, IEEE, Peter A. WATTERSON, \\ and Wei WU
}

\begin{abstract}
This paper reports the design, performance analysis, fabrication and experimental results of a three-phase, three-stack permanent magnet transverse flux motor with soft magnetic composite stator core, which was designed to take advantage of the unique properties of the new material. Parameter computations by finite element analysis of magnetic field and performance prediction by the equivalent electric circuit are discussed. To validate the simulation, a prototype motor has been fabricated and operated with a sensorless brushless DC drive scheme. The experimental results are thoroughly presented and agree with the theoretical calculations very well.
\end{abstract}

Index Terms-Transverse flux motor, permanent magnet motor, soft magnetic composite, 3D finite element analysis.

\section{INTRODUCTION}

$\mathrm{T}$ he study of transverse flux machines (TFMs) and their application in direct drive systems has become a topic of much interest since they were proposed by Weh and May in 1986 [1]. The TFM employs high energy density permanent magnets (PMs), simple toroidal windings, and a modular stator core, which guides the main flux through a path transverse to the direction of rotation [1, 2]. Because the armature magnetomotive force $(\mathrm{mmf})$ is applied to every pole, the TFM is capable of producing very high torque per unit volume provided that the pole number is high. TFMs are thus most suitable for direct drive applications demanding high torque at low speed, where the elimination of a gearbox can result in reduced weight, cost, losses and maintenance.

Disadvantages of TFMs include large inductance, which leads to low power factor [3], and complex structure with three-dimensional (3D) magnetic fields. It is very difficult to construct TFMs by using laminated steel sheets, which can only carry time varying magnetic flux in the plane of

Y. G. Guo is with the Faculty of Engineering, University of Technology, Sydney, P O Box 123, Broadway, NSW 2007, Australia (phone: +61-295147903; fax: +61-2-95142435; e-mail: youguang.guo-1@ uts.edu.au).

J. G. Zhu is with the Faculty of Engineering, University of Technology, Sydney, P O Box 123, Broadway, NSW 2007, Australia (e-mail: jianguo.zhu@uts.edu.au).

P. A. Watterson is with the Faculty of Engineering, University of Technology, Sydney, P O Box 123, Broadway, NSW 2007, Australia (e-mail: peter.watterson@uts.edu.au).

W. Wu is with GE Global Research, Niskayuna, NY 12309 (e-mail: wu@research.ge.com). laminations in order to maintain low eddy current loss.

Soft magnetic composite (SMC) materials have isotropic magnetic properties and low eddy current loss, making them potentially ideal for the armatures of 3D flux machines, such as claw pole and TFMs $[4,5]$. In these machines, the armature carries significant magnetic field in all three directions. This is only achievable using SMC material.

To investigate the application of SMC in TFMs, a threephase three-stack PM TFM with an SMC stator has been designed, fabricated and tested. The material's unique properties were taken into account in the motor design. The finite element analysis (FEA) of the 3D magnetic fields was conducted to compute the key parameters such as the stator winding flux, back electromotive force (emf), inductance, core loss and torque with or without stator currents, etc. The motor performance was predicted by an equivalent circuit, assuming the armature current in phase with the back emf for maximum torque (under the condition of optimum brushless DC control). The method for the motor design and performance analysis was validated by the experimental results on the prototype.

\section{Soft MAgnetic Composite}

Soft magnetic composite materials are produced from iron powders of high purity and compressibility. The powder particles are bonded with a coating of an organic material, which produces high electrical resistivity. The coated powder is then pressed into a die to form a solid magnetic core and finally heat treated to anneal and cure the bond $[5,6]$.

The powdered nature implies isotropic magnetic properties, which offers some key design advantages. The magnetic circuits can be designed with 3D magnetic flux paths and radically different topologies can be exploited to achieve high motor performances, because the restraints on magnetic field imposed by the lamination technology can be ignored.

Since the iron particles are coated with an electrically insulating layer, there is very little conduction between particles and the material tends to have much lower eddy current loss than laminated steels, particularly at higher frequencies. The total loss is dominated by magnetic hysteresis, which is higher than that of laminated steels due to the particle deformation during compaction. This property suggests that SMC motors are more likely to be advantageous at higher frequencies.

The most significant advantage of SMC materials may be 
the cost effective and environmentally friendly manufacturing, with minimum material waste, by using well-developed powder metallurgical techniques. Because the iron cores and parts can be compacted in a die into the desired net shape and dimensions, further machining is minimized and hence the production cost can be greatly reduced. Furthermore, SMC materials are easy to recycle.

Due to the significant economical and environmental benefits, SMC materials possess great potential for application in electrical machines, particularly those with complex structures.

However, SMC materials also have some outstanding drawbacks including lower magnetic permeability and lower saturation flux density compared with laminated steels. Simply replacing the laminated steel sheets by SMC will result in poorer machine performance. Therefore, it is important to avoid the disadvantages while exploiting the advantages in various stages, such as design, manufacturing and application. For example, SMC materials would be appropriate for construction of PM motors in which the magnetic circuit is dominated by the magnetic reluctance of the magnets, making such motors insensitive to the permeability of the core.

This paper presents a complete picture of our study on a three-phase three-stack PM transverse flux motor by using SMC as the stator core material. The initial design and simulated performance were reported in our previous work [7], but this paper adds more updated details and particularly, the experimental results on the prototype.

\section{Motor STRUCtURE AND Dimensions}

Fig. 1 illustrates the magnetically relevant parts of the TFM prototype with SMC an stator core. Table 1 lists the key dimensions and parameters, which were obtained for a motor with desired output power of $640 \mathrm{~W}$ at $1800 \mathrm{rev} / \mathrm{min}$.

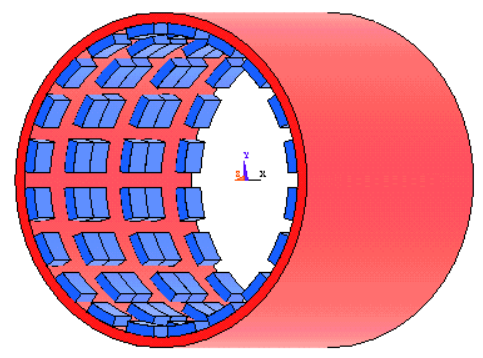

(a)

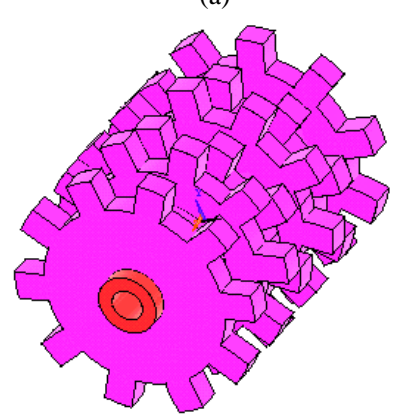

(b)

Fig. 1. Magnetically relevant parts of (a) rotor and (b) stator
TABLE I

KEY Dimensions AND DESIGN VARIABLES

\begin{tabular}{ll}
\hline \hline Dimension & Value \\
\hline Number of phases & 3 \\
Number of poles & 20 \\
Stator core material & SOMALOY $^{\mathrm{TM}} 500$ \\
Stator outer radius (mm) & 40 \\
Effective stator axial length $(\mathrm{mm})$ & 93 \\
Number of stator teeth & 60 \\
Rotor outer radius (mm) & 47 \\
Rotor inner radius (mm) & 41 \\
Permanent magnets & NdFeB, Grade N30M \\
Number of magnets & 120 \\
Magnet dimensions & OD88 x ID82 x 9 mm \\
& arc $12^{\circ}$ \\
Magnetization directions & Radial \\
Main airgap length (mm) & 1 \\
Number of coils & 3 \\
Coil window dimension $\left(\mathrm{mm}^{2}\right)$ & $15 \times 20.5$ \\
Number of turns & 125 \\
Diameter of copper wire $\left(\mathrm{mm}^{2}\right)$ & 1.25 \\
\hline \hline
\end{tabular}

The motor has an outer rotor comprising a mild steel cylinder with two arrays of magnets per phase mounted on the inner surface. The three phases of the motor are stacked axially with an angular shift of $120^{\circ}$ electrical from each other. Each stator phase has a single coil around an SMC core, which is molded in two halves. If the stator cores of the adjacent phases touch each other, the inductance of the phase winding in the middle may be significantly higher than that of the other two, causing an imbalance of phase winding inductance and difficulty for motor control. A silicon steel sheet, $0.65 \mathrm{~mm}$ thick, was inserted between the adjacent stator stacks of the prototype in an attempt to reduce the inter-phase flux leakage (given its skin depth was about $0.2 \mathrm{~mm}$ at $300 \mathrm{~Hz}$ ), but perhaps a copper sheet or airgap might have been used instead.

The motor main sizes, including the stator outer diameter and axial length of one stack, were basically determined by the dimensions of the available SOMALOY ${ }^{\mathrm{TM}} 500$ [8] preforms. They are the same as those of a claw pole SMC prototype we developed previously [9], enabling a comparison. A pole number of 20 was chosen giving an operating frequency of 300 $\mathrm{Hz}$ at $1800 \mathrm{rev} / \mathrm{min}$. This is not an unrealistically high frequency to work at for SMC materials.

Taking advantage of the isotropic magnetic property of the SMC material, the magnet axial length was designed longer than the tooth width to obtain a higher stator flux and hence higher specific torque.

Due to the lack of appropriate SMC preforms (i.e. with larger outer diameter), mild steel was used for the rotor yoke in this prototype. However, it should be noted that the motor performance such as efficiency would be better if SMC had been used because of the oscillating flux density.

Fig. 2(a) shows the "normal" arrangement of the rotor magnets, where the rotor inner surface is unrolled into a plane. However, this arrangement may cause very large flux leakage between the magnets of adjacent phases. Fig. 2(b) illustrates the actual magnet arrangement applied in the prototype.

For the magnet arrangements in both Figs. 2(a) and (b), the three stacks of the stator should be shifted by $120^{\circ}$ electrical 
from each other to produce a three-phase symmetrical emfs in the three windings and to minimize the cogging torque. The terminal polarities of the middle winding in Fig. 2(b) should be swapped because of the reversal of the flux direction in the middle phase.

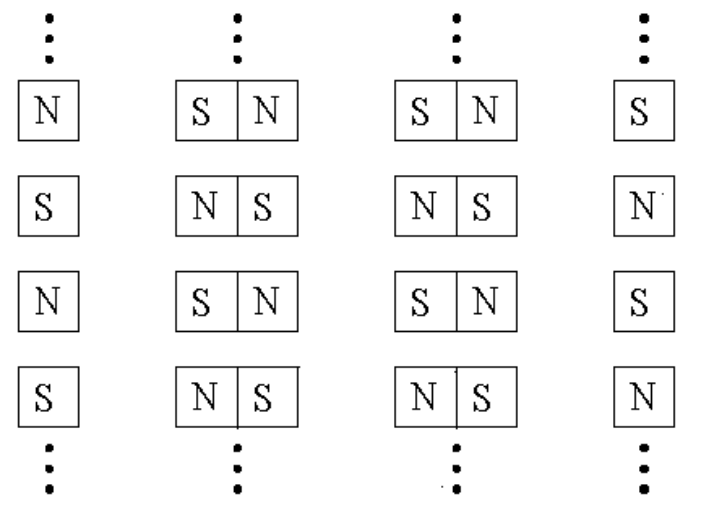

(a)
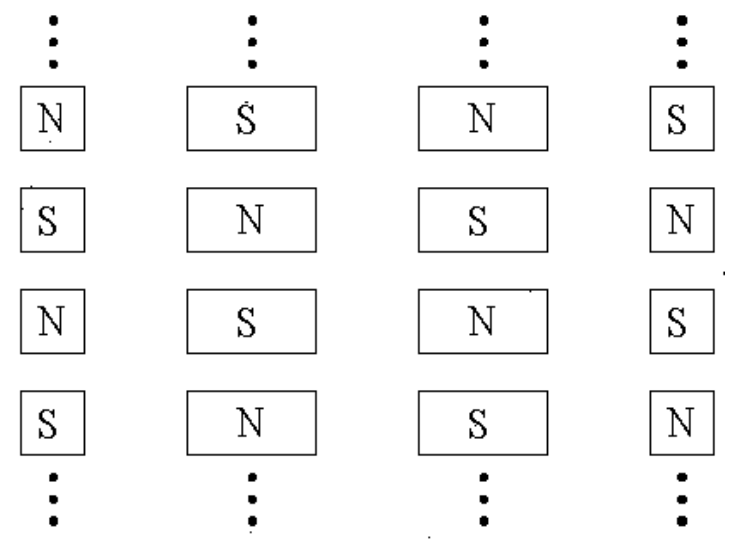

(b)

Fig. 2. Rotor magnet arrangement

\section{3D NUMERICAL FIELD ANALYSIS}

The magnetic flux path in the TFM is predominantly in planes containing the axes but becomes 3D as it spreads azimuthally to reduce flux densities. For non-linear material properties and accurate flux fringing calculation, a 3D FEA is required. Here, the commercial software package ANSYS was used. In the design of this prototype, the dimensions and parameters of the motor were first approximately determined by the magnetic circuit analysis and then refined by the FEA.

Taking advantage of the periodical symmetry, only one pole-pair region of the machine, as shown in Fig. 3, needs to be studied. At the two radial boundary planes, the magnetic scalar potential obeys the periodical boundary conditions:

$$
\varphi_{m}(r, \Delta \theta, z)=\varphi_{m}(r,-\Delta \theta, z)
$$

where $\Delta \theta=18^{\circ}$ mechanical is the angle of one pole pitch. The origin of the cylindrical coordinate is located at the center of the stack.

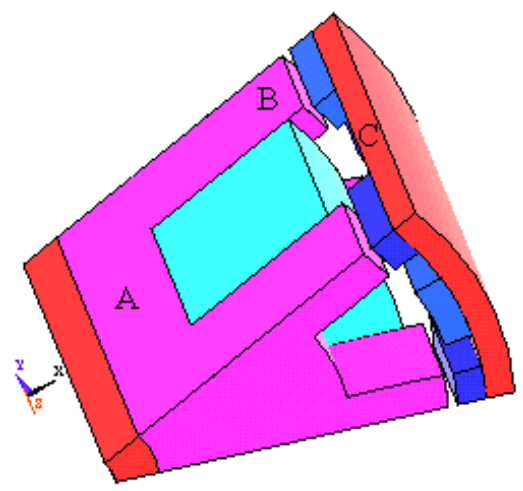

Fig. 3. Region for field solution

\section{A. Stator Winding Flux at No-load}

From the no-load magnetic field distribution solved by the FEA at multiple rotor angles, the magnetic flux linking the stator winding is obtained and differentiated to give the induced emf. As plotted in Fig. 4, this flux waveform versus the rotor position is calculated to be almost perfectly sinusoidal.

The inferred rms fundamental line-neutral back emf is

$$
E_{1}=k \omega_{r}
$$

where $\omega_{r}$ is the rotational angular frequency in mechanical $\mathrm{rad} / \mathrm{s}$ and the motor back emf constant $k=0.247 \mathrm{Vs}$ for the number of turns of the winding $N_{1}=125$ turns.

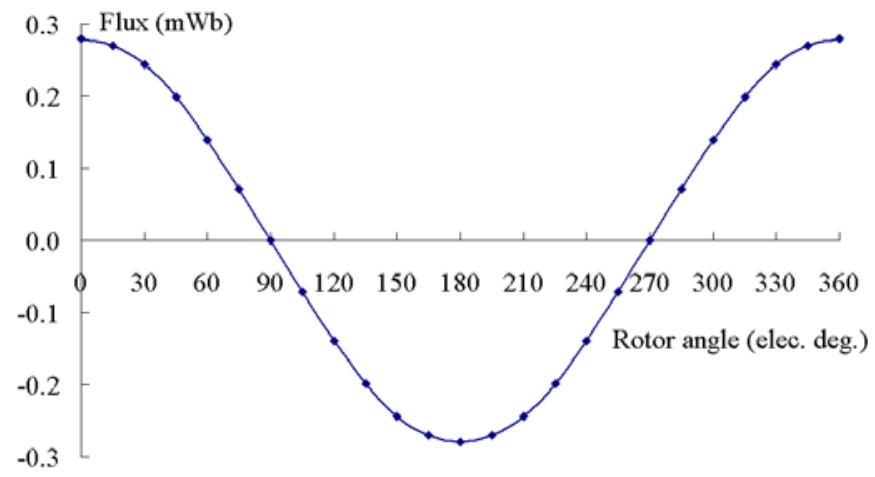

Fig. 4. No-load flux per turn of a phase winding

\section{B. Cogging Torque}

Cogging torque is caused by the tendency of the rotor magnets to line up with the stator teeth where the magnetic circuit has the highest permeance when the motor is under noload. Fig. 5 shows the cogging torque variation versus the rotor position for one phase of the machine, calculated by the Coulomb virtual work method in ANSYS [10].

The cogging torque of one phase has a period of $18^{\circ}$ mechanical (or $180^{\circ}$ electrical) and anti-symmetry about zero, and hence contains only even sine harmonics, which were obtained by the discrete Fourier transform, as expressed below

$$
\begin{aligned}
T_{A} \approx & -1.0303 \sin 2 \theta+0.1677 \sin 4 \theta-0.1130 \sin 6 \theta \\
& -0.0574 \sin 8 \theta-0.0107 \sin 10 \theta+0.0001 \sin 12 \theta(3)
\end{aligned}
$$


where $\theta$ is the rotor angular position in electrical degrees. Since the stator teeth of the three phases are shifted from each other by $120^{\circ}$ electrical, all even harmonics other than the $6^{\text {th }}$ order and its multiples sum to zero, and the cogging torque of the three-stack motor is

$T_{\text {cog }}=T_{A}+T_{B}+T_{C} \approx-0.3390 \sin 6 \theta+0.0003 \sin 12 \theta$

As shown in Fig. 6, the theoretical prediction agrees well with the experimental measurement.

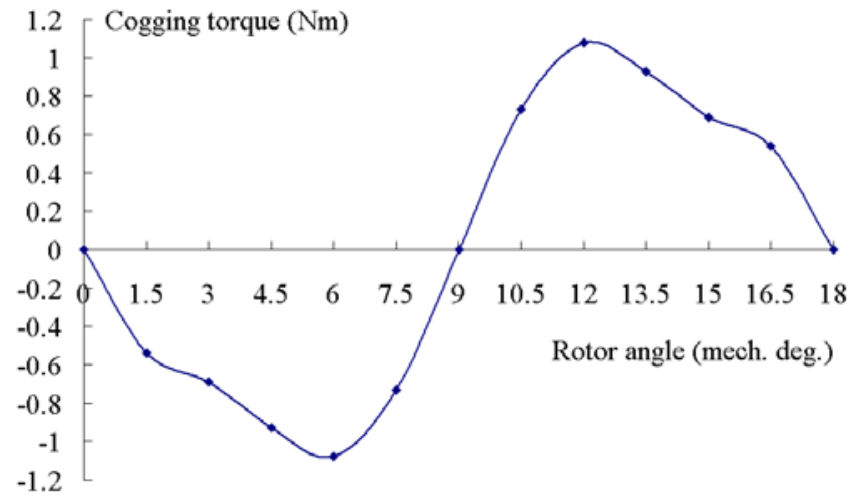

Fig. 5. Calculated cogging torque versus rotor angle for one stack

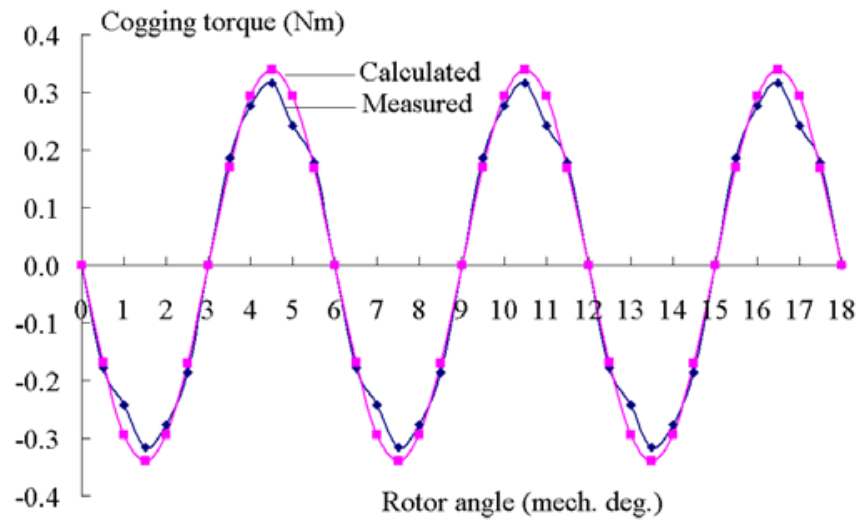

Fig. 6. Calculated and measured cogging torque for the three-stack motor

\section{Inductance and Armature Reaction}

The self-inductance of each phase winding can be calculated by

$$
L_{1}=\frac{N_{1} \phi_{1}}{I_{1}}
$$

where $\phi_{1}$ is the magnitude of the flux linking the stator winding due to a stator current $I_{1}$ in each of $N_{1}$ turns. It can be obtained from the results of a field analysis with a stator current $I_{1}$ while the permanent magnets are "switched off", i.e. remanence is set to zero.

From Table II, it can be seen that the per-turn inductance is very uniform against the rotor angles. The inductance scales as $N_{1}{ }^{2}$ and so is $6.68 \mathrm{mH}$ for 125 turns. It is also shown in Table II that the armature reaction for the rated current is about $0.1 \mathrm{~T}$ in the magnets and will not demagnetize them.

TABLE II

PER-TURN INDUCTANCE AND ARMATURE REACTION IN MAGNETS

\begin{tabular}{lll}
\hline \hline $\begin{array}{l}\text { Rotor position } \\
\text { (electrical degrees) }\end{array}$ & $\begin{array}{l}\text { Self inductance } \\
(\mu \mathrm{H})\end{array}$ & $\begin{array}{l}\text { Maximum B in } \\
\text { magnets }(\mathrm{T})\end{array}$ \\
\hline 0 & 0.4279 & 0.099 \\
30 & 0.4277 & 0.099 \\
60 & 0.4275 & 0.102 \\
90 & 0.4277 & 0.099 \\
\hline \hline
\end{tabular}

\section{Core Loss Calculation}

Due to the 3D nature of the magnetic fields in the TFM, the flux density locus at one position can be either alternating with or without harmonics, two-dimensional (2D) or even 3D rotating with either purely circular or elliptical patterns. Fig. 7 plots the calculated 3D flux density locus (solid line) and its projections (dot lines) in the $\mathrm{ro} \theta, \theta \mathrm{oz}$, and zo $\theta$ planes in a typical element in a stator tooth (Point B in Fig. 3), showing that the flux density vector in the tooth is rotating elliptically in the 3D space.

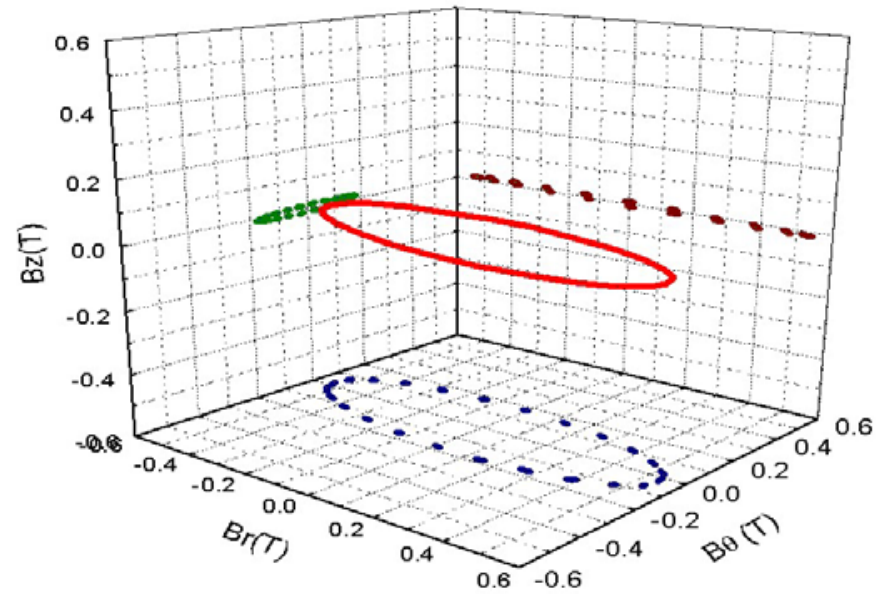

Fig. 7. Flux density locus in a typical element in the stator tooth

Core losses caused by different patterns of flux density loci are very different. An improved method proposed specifically for prediction of core losses in 3D flux SMC motors [11, 12] is employed for the core loss analysis presented in this paper. This method calculates the total core loss of a motor by summing up the core losses dissipated in each finite element, which is calculated by various formulae according to the locus pattern of the rotating magnetic flux density vector obtained by the 3D FEA when the rotor rotates for a pole pitch (an example is shown in Fig. 7). The SMC stator core loss was calculated to be $29 \mathrm{~W}$ at no-load at $1800 \mathrm{rev} / \mathrm{min}$.

\section{PERformance Prediction}

\section{A. Stator Winding Resistance and Reactance}

The resistance of the stator winding can be calculated by

$$
R_{1}=\frac{\rho l_{1}}{A_{1}}
$$


where $l_{1}$ is the total wire length in $\mathrm{m}, A_{1}$ the wire cross sectional area in $\mathrm{m}^{2}$, and $\rho$ the electrical resistivity in $\Omega \mathrm{m}$ of the stator winding. The calculated phase winding resistance is $0.310 \Omega$ at $20^{\circ} \mathrm{C}$.

The synchronous reactance of the stator winding is calculated by

$$
X_{1}=2 \pi f_{1} L_{1}
$$

where $f_{1}$ is the operating frequency and $L_{1}$ is the synchronous inductance of the stator winding in Henry. In the case of this three-phase three-stack motor, $L_{1}$ equals the self-inductance of the stator winding.

\section{B. Power, Torque and Efficiency}

The motor is operated with a $120^{\circ}$ conduction, square wave brushless DC drive scheme. Under the condition of optimum rotor position feedback, i.e. the current $I_{1}$ is controlled to be in phase with the induced emf, $E_{1}$ in the stator winding, the achievable maximum electromagnetic power $P_{e m}$ is

$$
P_{e m}=3 E_{1} I_{1}
$$

The output power, output torque, input power and efficiency can then be calculated by

$$
\begin{aligned}
& P_{\text {out }}=P_{\text {em }}-P_{F e}-P_{\text {mec }} \\
& T_{\text {out }}=P_{\text {out }} / \omega_{r} \\
& P_{\text {in }}=P_{\text {em }}+P_{\text {inv }}+P_{c u} \\
& P_{c u}=3 I_{1}^{2} R_{1} \\
& \eta=P_{\text {out }} / P_{\text {in }}
\end{aligned}
$$

where $P_{F e}$ is the core loss, $P_{\text {mec }}$ the mechanical loss, $P_{i n v}$ the inverter conduction loss, $P_{c u}$ the copper loss, which is assumed here to be dominated by the fundamental component of current, and $\omega_{r}$ the rotor angular speed in mechanical rad/s.

\section{DC Voltage and Current of the Inverter}

The cost of the drive is largely related to the inverter input power, or the input DC voltage and current, which can be estimated from the ratings of the motor.

The line-to-neutral $r m s$ voltage and phase rms current have the following relationship when the motor is under optimum brushless DC control:

$$
V_{1}=\sqrt{\left(E_{1}+I_{1} R_{1}\right)^{2}+\left(I_{1} X_{1}\right)^{2}}
$$

The corresponding DC input voltage of the inverter can be approximately estimated by

$$
V_{d c}=2.34 V_{1}
$$

though this formula is derived for no-load [13]. If PWM is not used in the inverter and switching takes place at the optimum time, the mean DC supply current $I_{d c}$ is related approximately to the AC line rms fundamental current $I_{a c}$ (i.e. $I_{1}$ ) by [13]

$$
I_{d c}=(1.00 \sim 1.28) I_{a c}
$$

The coefficient is dependent upon the load and other factors such as the current waveform.

\section{Thermal Analysis}

To obtain an economic utilization of the materials and safe operation of the motor it is necessary to predict with reasonable accuracy the temperature rise of the internal parts, especially in the coils and magnets. In this study, the temperature rise was calculated by using a hybrid thermal network model with distributed heat sources, shown in Fig. 8. For higher computation accuracy, any part, e.g. the airgap, could be divided into more segments.

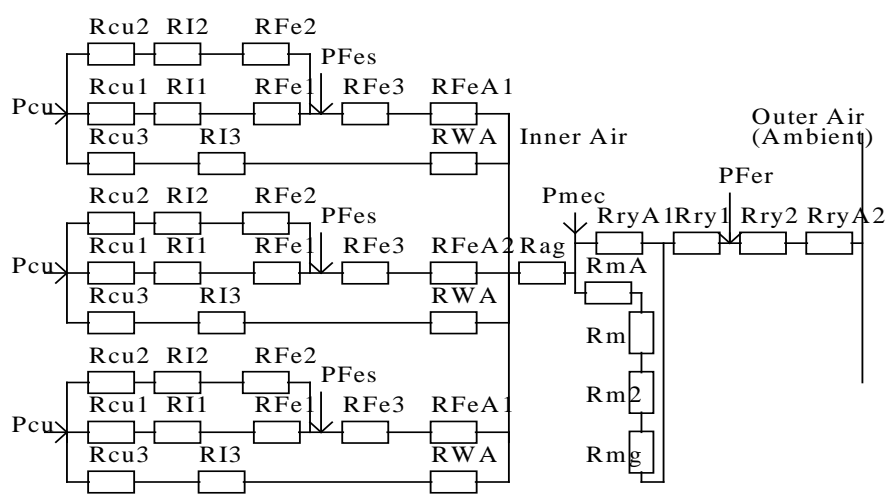

Fig. 8. Thermal network model of the TFM prototype

The thermal resistances of conduction in the following sections are calculated: rotor yoke $\left(R_{r y}\right)$, magnets $\left(R_{m}\right)$, glue between magnet and rotor yoke $\left(R_{m g}\right)$, air gap $\left(R_{a g}\right)$, stator yoke $\left(R_{F e 1}\right)$, stator side discs $\left(R_{F e 2}\right)$, stator teeth $\left(R_{F e 3}\right)$, varnished copper wire $\left(R_{c u}\right)$ and insulations $\left(R_{I 1}, R_{I 2}, R_{I 3}\right)$ between the winding and the stator yoke, the stator wall disc and the air gap, respectively. In addition, the thermal resistances of the stator shaft $\left(R_{s s}\right)$, the aluminum end plates $\left(R_{a l}\right)$ and the stationary air $\left(R_{s a}\right)$ between the side discs and the end plates are calculated separately.

The equivalent thermal resistances to the heat convection of the following sections are calculated: between the stator tooth surface and the inner air in the airgap $\left(R_{F e A}\right)$, between the winding and the inner air $\left(R_{W A}\right)$, between the magnet and the inner air $\left(R_{m A}\right)$, between the rotor yoke and the inner air $\left(R_{r y A 1}\right)$, between the rotor yoke and the outer air $\left(R_{r y A 2}\right)$.

The heat sources include the stator coil copper losses $\left(P_{c u}\right)$, the stator and rotor core losses $\left(P_{F e s}, P_{F e r}\right)$, and the mechanical losses due to windage and friction $\left(P_{\text {mec }}\right)$. The improved method for core loss calculation can obtain the loss distribution, which is a great advantage for the thermal calculation by the hybrid thermal model. 
The temperature rises at the middle points of several parts are calculated as $64.9^{\circ} \mathrm{C}$ in the coil, $78.6^{\circ} \mathrm{C}$ in the stator core, $59.3^{\circ} \mathrm{C}$ in the air gap, $36.1^{\circ} \mathrm{C}$ in the magnets, and $25.3^{\circ} \mathrm{C}$ on the rotor yoke outer surface.

\section{EXPERIMENT VALIDATION}

\section{A. Test Rig}

Fig. 9 shows the test rig of the 3-phase 3-stack PM SMC transverse flux motor (on the right). A printed circuit disc armature DC machine (on the left but not shown) is connected via a torque transducer (in the middle) as the load when the prototype is operated as a motor, or the driver when the prototype is operated as a generator. Although only three terminals of the 3-phase star-connection winding are needed for the motor operation, the common point was also connected externally for measurement convenience. Two thermocouples are embedded in the windings for temperature monitoring.

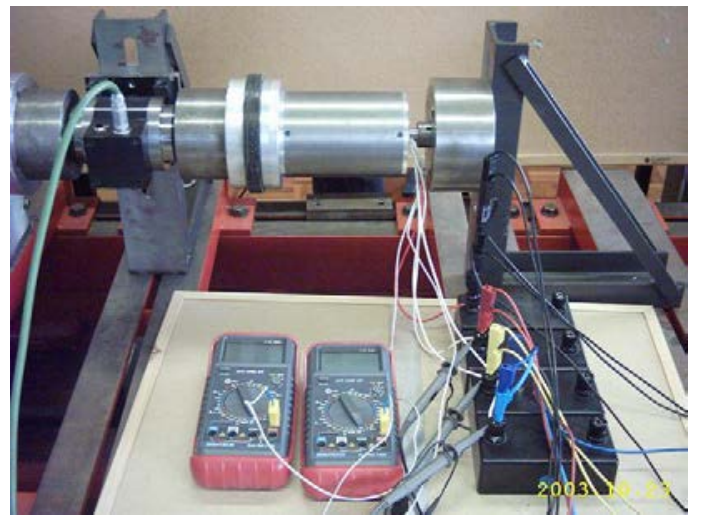

Fig.9. Testing set-up of a PM transverse flux motor with SMC stator

\section{B. Resistance and Inductance Measurement}

The phase resistance was inferred from the voltage $V_{d c}$ across the winding for a DC current $I_{d c}$ of 1 A by

$$
R_{1}=V_{d c} / I_{d c}
$$

The measured phase resistance was $0.305 \Omega$ at room temperature $\left(20^{\circ} \mathrm{C}\right)$. The phase self-inductances were measured by a digital multi-functional meter, TES 2639, which applied a square wave voltage excitation of about $200 \mathrm{~Hz}$ to the winding and inferred the inductance from the rms value of the applied voltage fundamental and the measured rms current (about 10 $\mathrm{mA}$ ). The measured inductances were $6.33 \mathrm{mH}$ for the two side stacks and $6.94 \mathrm{mH}$ for the middle stack, averaging to $6.53 \mathrm{mH}$. The measured resistance and inductance (averaged) are in a good agreement with the prediction $(0.310 \Omega$ and 6.68 $\mathrm{mH}$ ), being $1 \%$ and $2 \%$ lower respectively.

The stacks are considered as magnetically independent. It was anticipated that the low skin depth in the $0.65 \mathrm{~mm}$ thick steel sheet might have stopped flux leakage between phases, but the variation in measured inductance suggests that this was not successful. Flux leakage between phases may also have occurred via the mild steel shaft used.

\section{Measurement of Back emf Waveform}

When the prototype operates as a generator, driven by the DC machine, the back electromotive force can be measured from the open circuit voltage.

The three phase voltage waveforms are recorded by a 4channel digital Tektronix CRO. The data of three waveforms are saved in a PC for further analysis and the phase shifts between the three waveforms can also be checked. Fig. 10 shows the measured emf waveforms at $1800 \mathrm{rev} / \mathrm{min}$ or 300 Hz. They are very close to sinusoidal. These three phase emf waveforms are the same in magnitude but are shifted with relative to each other by $120^{\circ}$ electrical, as expected. The measured motor back emf constant in (2) was $k=0.244 \mathrm{Vs}$, $1 \%$ lower than the predicted, $0.247 \mathrm{Vs}$.

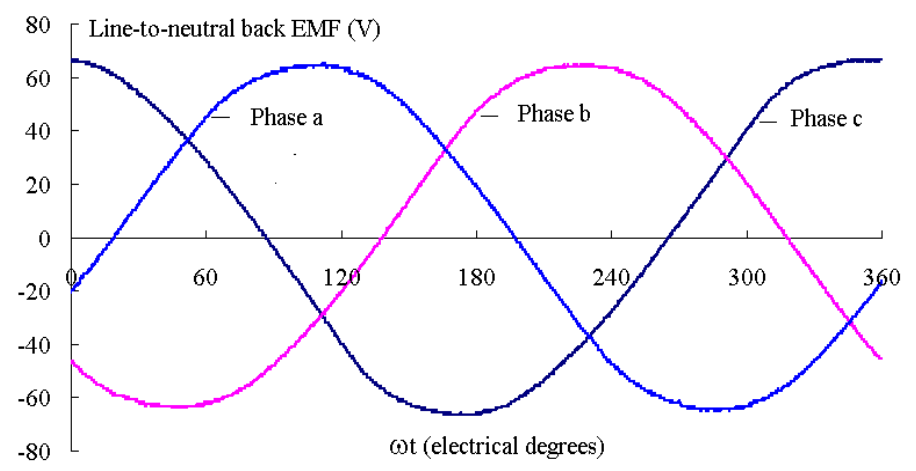

Fig.10. Measured emf waveforms at $1800 \mathrm{rev} / \mathrm{min}$

\section{Measurement of Cogging Torque}

For the measurement of cogging torque, the stator is mounted on a rotatable air-bearing plate with very little mechanical friction. By displacing the stator with the rotor fixed, the cogging torque was measured by a spring balance and plotted in Fig. 6. It substantially matches the theoretical calculation (4), with a peak of $0.32 \mathrm{Nm}$, just $6 \%$ lower than predicted.

\section{E. Core Loss and Mechanical loss Measurement}

The core loss at no-load is measured by separating the core loss from the mechanical loss using the dummy stator method, which includes two measurements. In the first measurement, the prototype is driven by the DC motor and the DC motor electromagnetic power $P_{e m 1}$ is recorded, being the DC motor input power minus the copper loss. The second measurement giving $P_{e m 2}$ is conducted while the SMC stator of the prototype is replaced by a wooden tube.

Assuming the core loss and mechanical loss in the DC driving motor can be taken as constant at each rotor speed, the difference $P_{e m 1}-P_{e m 2}$ gives the core loss $P_{F e}$, shown in Fig. 11 . This curve is well-fitted by the following simple model, separating the loss into a hysteresis component proportional to the speed and an eddy current component proportional to the speed squared

$$
P_{\mathrm{Fe}}=c_{h} \omega_{r}+c_{e} \omega_{r}^{2}
$$


with $c_{h}=0.18 \mathrm{Ws}$ and $c_{e}=9.98 \times 10^{-4} \mathrm{Ws}^{2}$. At $1800 \mathrm{rev} / \mathrm{min}$, the hysteresis loss is $34 \mathrm{~W}$ and the eddy current loss $35 \mathrm{~W}$. Since the hysteresis loss dominates in the SMC stator core, the measurement is consistent with the calculated SMC loss of 29 $\mathrm{W}$ if there is $5 \mathrm{~W}$ additional hysteresis loss in the mild steel rotor.

The SMC motor mechanical loss, comprising windage and bearing friction, was inferred by subtracting the DC motor electromagnetic power with the SMC motor disconnected $P_{e m 3}$ from the dummy stator test result $P_{e m 2}$, and is shown in Fig. 11 . At $1800 \mathrm{rev} / \mathrm{min}$ the mechanical loss was $6 \mathrm{~W}$.

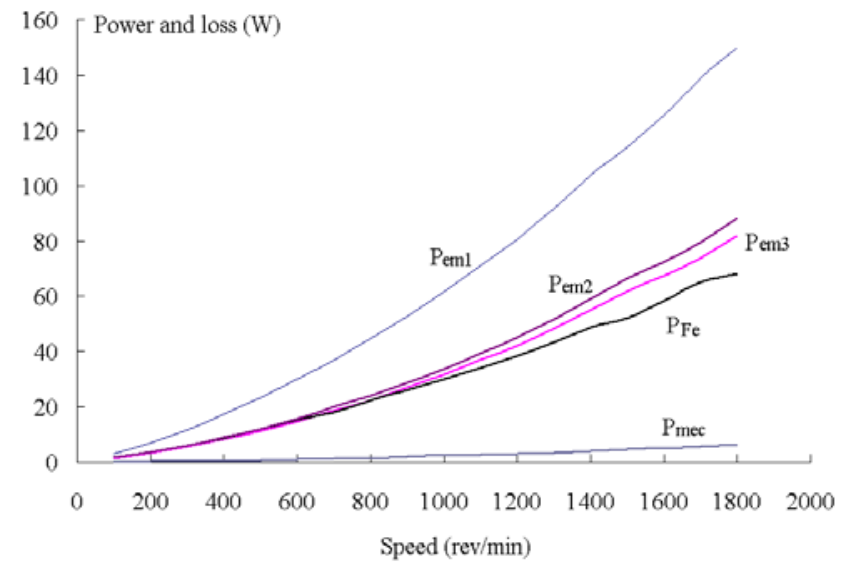

Fig. 11. DC motor electromagnetic powers and inferred SMC motor core loss and mechanical loss versus rotor speed

\section{F. Steady State Characteristics}

The prototype was operated with a 6-step $120^{\circ}$ conduction inverter with a sensorless algorithm which approximately keeps the current and back emf aligned.

1) No-load Test: Because the DC machine is always coupled to the prototype via the torque transducer, the no-load test conducted with the DC machine open-circuited is actually not ideally no-load. Figs. 12-14 plot the curves of the motor speed, AC voltage, AC and DC currents against the inverter DC link voltage. As shown, the 3-phase AC machine behaves like a DC motor. When the DC link voltage increases, the rotor speed goes up linearly. The ratio between the DC and AC voltages averages to 2.34 and the ratio between the currents is about 1.20 as expected by (15) and (16).

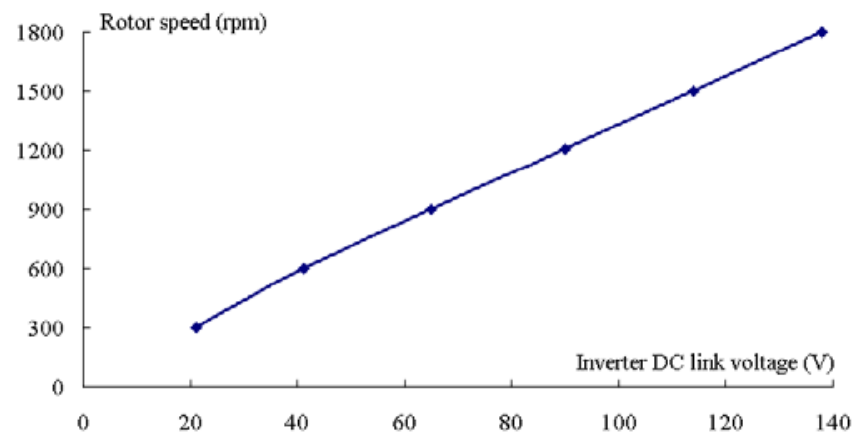

Fig. 12. Curve of the motor speed against the inverter DC link voltage

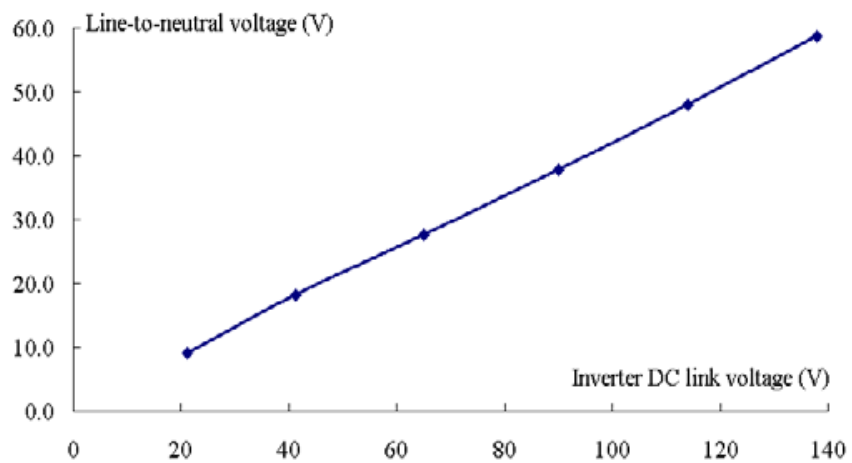

Fig. 13. Curve of the line-to-neutral voltage against the DC link voltage

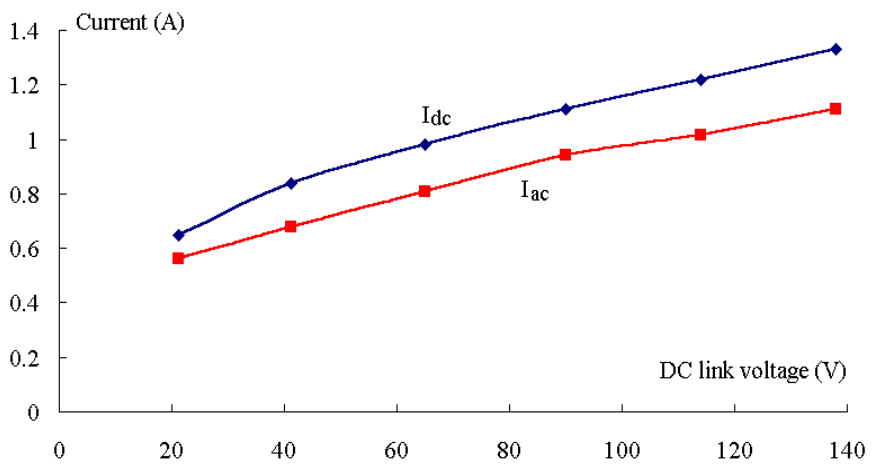

Fig. 14. Curves of the DC link and AC line currents against DC link voltage

2) Load Test: The steady state characteristics were measured under load by applying a variable load resistance to the DC generator output terminals. Fig. 15 shows the mechanical characteristic of speed versus the output torque for a fixed DC link voltage, $192 \mathrm{~V}$ and Fig. 16 shows the variations of the input power, output power and efficiency against the output torque. The load test is also conducted with different inverter DC link voltages and the corresponding mechanical characteristics are plotted in Fig. 17.

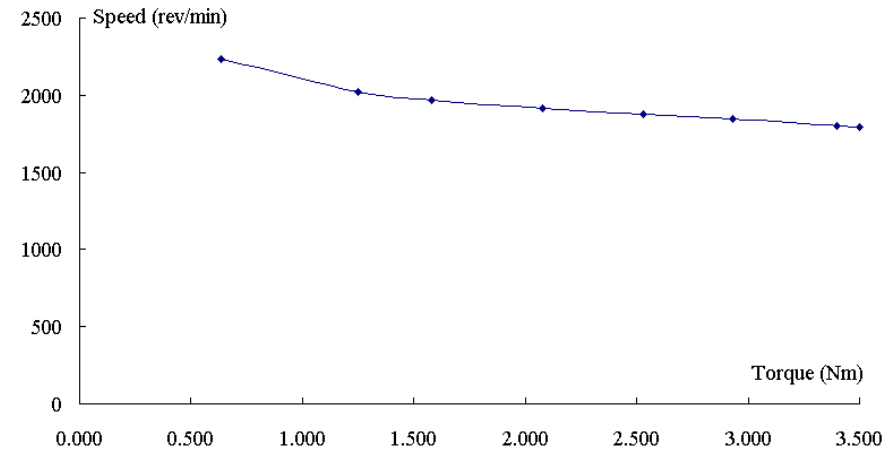

Fig. 15. Speed against output torque with inverter DC link voltage $192 \mathrm{~V}$ 


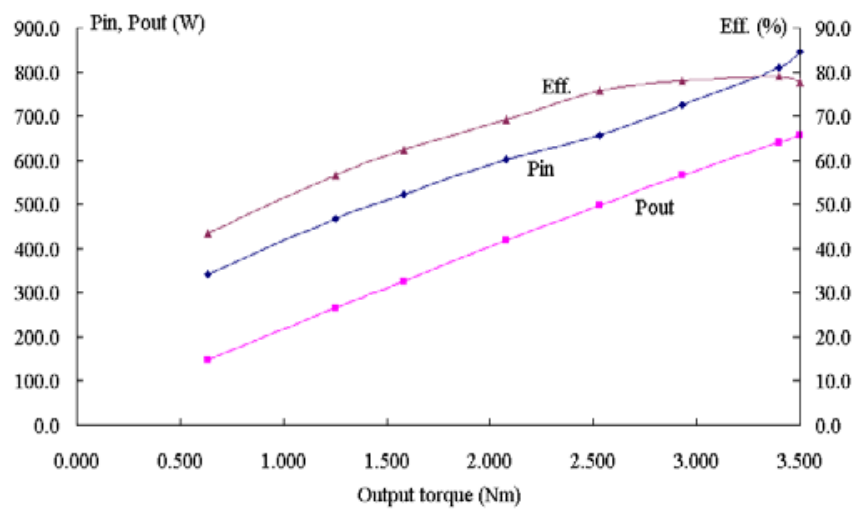

Fig. 16. Curves of inverter input power, motor output power and efficiency versus output torque

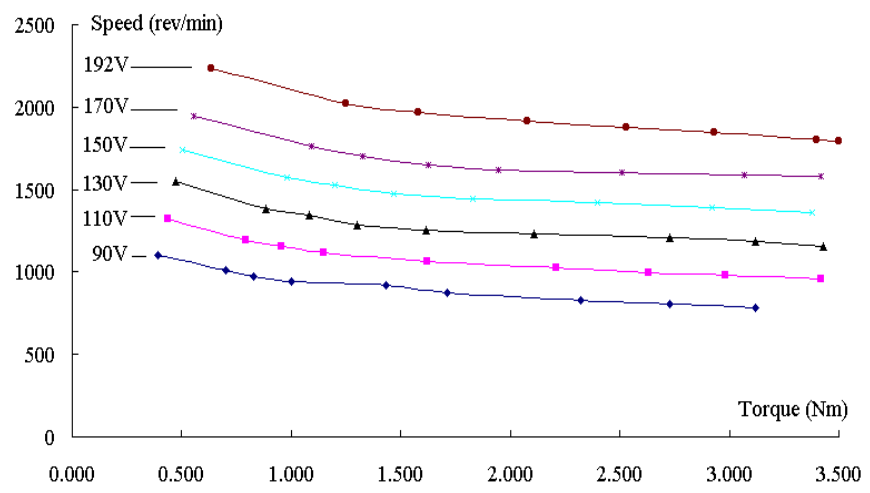

Fig. 17. Speed against output torque with different DC link voltages

\section{G. Measurement of Temperature Rise}

The winding temperature was measured by the buried thermocouples. When the prototype has been run at full load for 30 minutes, the temperature reading becomes stable. The stator coil temperature was measured as $86^{\circ} \mathrm{C}$ with an ambient temperature of $20^{\circ} \mathrm{C}$ (or $66^{\circ} \mathrm{C}$ temperature rise). The rotor yoke surface temperature was measured to be $47^{\circ} \mathrm{C}$ (or $27^{\circ} \mathrm{C}$ temperature rise) by an infrared temperature probe. They agree closely with the previous calculated temperature rises of $65^{\circ} \mathrm{C}$ and $25^{\circ} \mathrm{C}$ respectively.

\section{H. Summary of Performance}

Table III summarizes the predicted and measured motor parameters and Table IV gives the measured performance under the rated conditions.

TABLE III

Key MOTOR PARAMETERS

\begin{tabular}{lll}
\hline \hline Parameter & Predicted & Measured \\
\hline Motor back emf constant $(\mathrm{Vs})$ & 0.247 & 0.244 \\
Phase resistance at $20^{\circ} \mathrm{C}(\Omega)$ & 0.310 & 0.305 \\
Phase (synchronous) inductance $(\mathrm{mH})$ & 6.68 & 6.53 \\
Cogging torque maximum $(\mathrm{Nm})$ & 0.339 & 0.32 \\
\hline \hline
\end{tabular}

TABLE IV

MEASURED Motor PeRFoRMANCE AT RATEd CONDITIONS

\begin{tabular}{ll}
\hline \hline Parameter & Value \\
\hline Speed (rev/min) & 1800 \\
Frequency (Hz) & 300 \\
Inverter DC link voltage (V) & 192 \\
Input power (W) & 805 \\
Output power (W) & 640 \\
Total drive efficiency (\%) & 79.5 \\
Phase current (A) & 5.5 \\
Copper loss (W) & 36 \\
Core loss (W) & 112 \\
Inverter loss (W) & 11 \\
Mechanical and windage loss (W) & 6 \\
Winding temperature rise $\left({ }^{\circ} \mathrm{C}\right)$ & 66 \\
\hline \hline
\end{tabular}

The inverter loss has been calculated from the phase current and MOSFET conduction resistance, with switching loss assumed small.

It is noted that under the rated conditions, the core loss has increased by about $62 \%$ from the no-load value at 1800 $\mathrm{rev} / \mathrm{min}$ of $69 \mathrm{~W}$ to the rated load value of $112 \mathrm{~W}$. This increase can be attributed to the increase of flux density due to the large armature reactance, and possibly harmonics in the flux density generated by the six-step switching used.

\section{COMPARISON WITH OTHER MOTORS}

In Table $\mathrm{V}$, the measured performance of the SMC transverse flux motor is compared with two other commercial laminated motors and an SMC claw pole motor.

TABLE V

COMPARISON WITH OTHER MOTORS

\begin{tabular}{|c|c|c|c|c|}
\hline Parameter & $\begin{array}{l}\text { SMC } \\
\text { TFM }\end{array}$ & $\begin{array}{l}\text { Induction } \\
\text { motor }\end{array}$ & $\begin{array}{l}\text { Radial field } \\
\text { brushess DC }\end{array}$ & $\begin{array}{l}\text { SMC } \\
\text { claw pole }\end{array}$ \\
\hline Output power (W) & 640 & 550 & 1084 & 500 \\
\hline Torque (Nm) & 3.4 & 3.72 & 3.45 & 2.65 \\
\hline Speed (rev/min) & 1800 & 1410 & 3000 & 1800 \\
\hline $\begin{array}{l}\text { Total drive } \\
\text { efficiency (\%) }\end{array}$ & 79.5 & 75 & Not given & 81 \\
\hline $\begin{array}{l}\text { Coil temperature } \\
\text { rise }\left({ }^{\circ} \mathrm{C}\right)\end{array}$ & 66 & 80 & 65 & 71 \\
\hline Axial length (mm) & 137 & 234 & 217 & 137 \\
\hline $\mathrm{OD}(\mathrm{mm})$ & 94 & 160 & 100 (square) & 94 \\
\hline $\begin{array}{l}\text { Torque per unit } \\
\text { volume }\left(\mathrm{Nm} / \mathrm{m}^{3}\right)\end{array}$ & 3576 & 791 & 1590 & 2787 \\
\hline $\begin{array}{l}\text { Power per unit } \\
\text { volume }\left(\mathrm{W} / \mathrm{m}^{3}\right)\end{array}$ & $\begin{array}{l}6.73 \\
\times 10^{5}\end{array}$ & $\begin{array}{l}1.17 \\
\times 10^{5}\end{array}$ & $\begin{array}{l}5.00 \\
\times 10^{5}\end{array}$ & $\begin{array}{l}5.26 \\
\times 10^{5}\end{array}$ \\
\hline
\end{tabular}

The induction motor listed is an aluminum frame TEFV (Totally Enclosed Fan Ventilated) "high efficiency" induction motor [14] rated $3.72 \mathrm{Nm}$ (9\% higher than the SMC motor) at $1410 \mathrm{rev} / \mathrm{min}, 75 \%$ efficiency, $80^{\circ} \mathrm{C}$ temperature rise [15]. Though the performance is slightly lower than the SMC motor, the induction motor size is much larger, with an outer diameter (OD) of $160 \mathrm{~mm}$ including fins and total length of $234 \mathrm{~mm}$ including fan but excluding shaft. The SMC motor features a 
torque per unit volume 4.5 times that of the laminated induction motor.

The second comparison is with a radial field $\mathrm{NdFeB}$ brushless DC servo motor [16] with the same torque rating (accepting manufacturer's assumed mounting to a cooled $25^{\circ} \mathrm{C}$ flange) though higher speed capability (3000 rev/min). The SMC transverse flux motor delivers 2.25 times the torque per unit volume and 1.35 times power per unit volume than this servo motor.

The final colum of Table $\mathrm{V}$ gives the figures of the SMC claw pole motor prototype described in [9]. For identical speed and external dimensions, the TFM motor achieved $28 \%$ higher output power, with a $7 \%$ lower temperature rise though a higher total loss, which may be due to the fact that the loss generated in the external rotor yoke (high in the TFM but negligble in the claw pole motor) could be easily dissipated. The SMC transverse flux motor is seen to be slightly superior to the SMC claw pole motor.

\section{DISCUSSION AND CONCLUSION}

To investigate the potential of SMC material in manufacturing small motors of complex structures, a 3-phase PM transverse flux motor with SMC core has been designed, taking into account the unique properties of the material. The method for the motor design and performance analysis has been validated by the good agreement with the experimental results; the back emf, inductance, cogging torque, input power, output power and torque, efficiency and temperature rise were all predicted within a few percents.

The stator of just 6 pressed SMC discs and 3 circular coils offers potentially reduced manufacturing cost compared to the conventional, laminated stator motors with distributed windings. It must be admitted that there would be some additional cost in handling the 120 magnets used, but the material cost would be acceptable, of order AU $\$ 15$ (based on $220 \mathrm{~g}$ at $\mathrm{AU} \$ 70 / \mathrm{kg}$ ).

The SMC TFM performance is shown to be superior in specific torque and power to a sample commercial induction motor and a brushless DC servomotor, both with laminated electrical steel cores. Furthermore, the SMC motor rated performance was reported at $640 \mathrm{~W}$ output and $1800 \mathrm{rev} / \mathrm{min}$, partly to enable comparison with the SMC claw pole motor and partly because the sensorless switching inverter, which kept current and back emf nearly aligned, proved unstable at higher torques. Higher specific torque and power could probably have been achieved at a lower speed, especially with an inverter which enabled flux-weakening to reduce the increase in iron loss due to the armature reaction.

It should also be noted that using the double-sided flux concentration [1, 2] in TFMs would produce a higher specific power or torque. In this paper, the single-sided surfacemounted PM type was chosen for simple fabrication, but still produced a quite encouraging performance.

\section{ACKNOWLEDGMENT}

The authors gratefully thank Höganäs $A B$, Sweden, for supplying preforms of SOMALOY 500 .

\section{REFERENCES}

[1] H. Weh and H. May, "Achievable force densities for permanent magnet excited machines in new configuration," in Proc. Int. Conf. on Electrical Machines, Munich, Germany, Sept. 1986, pp. 1107-1111.

[2] H. Weh, H. Hoffmann, and J. Landrath, "New permanent magnet excited synchronous machine with high efficiency at low speed," in Proc. Int. Conf. on Electrical Machines, Italy, Sept. 1988, pp. 35-40.

[3] M. R. Harris, G. H. Pajooman, and S. M. Abu Sharkh, "The problem of power factor in VRPM (transverse-flux) machines," in Proc. IEE Colloq. on Electrical Machines and Drives, Sept. 1997, pp. 386-390.

[4] Y.G. Guo, J.G. Zhu, P.A. Watterson, and W. Wu, "Comparative study of 3-D flux electrical machines with soft magnetic composite core", IEEE Trans. Ind. Applicat., Vol.39, Nov./Dec. 2003, pp.1696-1703.

[5] A. G. Jack, "Experience with the use of soft magnetic composites in electrical machines," in Proc. Int. Conf. on Electrical Machines, Istanbul, Turkey, 1998, pp. 1441-1448.

[6] M. Persson, P. Jansson, A. G. Jack, and B. C. Mecrow, "Soft magnetic composite materials - use for electrical machines," in Proc. IEE Conf. on Electrical Machines and Drives, London, Sept. 1995, pp. 242-246.

[7] Y.G. Guo, J.G. Zhu, P.A. Watterson, and W. Wu, "Design and analysis of a transverse flux machine with soft magnetic composite core," in Proc. Int. Conf. on Electrical Machines and Sys., Beijing, Nov. 2003, pp. 153-157

[8] "Soft magnetic composites from Höganäs metal powders SOMALOY ${ }^{\text {TM }}$ 500”, Höganäs catalogue, SMC 97-1.

[9] Y.G. Guo, J.G. Zhu, P.A. Watterson, W.M. Holliday, and W. Wu, "Improved design and performance analysis of a claw pole permanent magnet SMC motor with sensorless brushless DC drive," IEEE Int. Conf. on Power Electronics and Drive Syst., Singapore, Nov. 2003, pp. 704-709

[10] J. L. Coulomb and G. Meunier, "Finite element implementation of virtual work principle for magnetic or electrical force and torque computation,” IEEE Trans. Magn., vol.20, pp. 1894-1896, Sept. 1984.

[11] Y. G. Guo, J. G. Zhu, J. J. Zhong, and W. Wu, "Core losses in claw pole permanent magnet machines with soft magnetic composite stators," IEEE Trans. Magn.,vol.39, pp. 3199-3201, Sept. 2003.

[12] Y. G. Guo, J. G. Zhu, J. J. Zhong, P. A. Watterson, and W. Wu, “An improved method for predicting magnetic power losses in SMC electrical machines," Int. J. Applied Electromagnetics and Mechanics, vol.19, pp. 75-78, 2004.

[13] P. A. Watterson, "Analysis of six-step $120^{\circ}$ conduction permanent magnet drives," in Proc. Australasian Uni. Power Eng. Conf., Sydney, Australia, 1997, pp. 13-18.

[14] "W high efficiency aluminum motors," Product Manuals of Brook Crompton 2100 Issue $3 e$.

[15] "Product catalogue for 3 phase induction motor," Product Manuals of Brook Crompton.

[16] "FAS T series brushless servomotors," Vickers Catalogue EPC-GB-B4030, Motor FAS T1 M4 030, 1991. 